\title{
El desenvolvimiento identitario de la Acción Católica como comunidad de sentido
}

El catolicismo mexicano suele encontrar oídos atentos entre los de la academia. El catolicismo social está afianzado en la representación de ser una reacción bien articulada frente a las políticas secularizantes de los Gobiernos en turno, y también ante la misma tendencia en las instituciones socioculturales.

En consonancia con el posicionamiento eclesial respecto de estas políticas, se determinaría la fundación, en 1929, de la Acción Católica Mexicana (ACM). Esta organización, como expresión mexicana del catolicismo social, se convirtió en objeto de interés de las más diversas investigaciones historiográficas y antropológicas, entre las que se hace hincapié en la dimensión socioreligiosa.

En algunas de ellas, no obstante se ocupan de diferentes maneras del elemento identitario, poco se conoce al sujeto que le daría vida; en el mejor de los casos, se le puede ver en su sujeción a la institución católica y el discurso a partir del

Profesora del Departamento de Filosofía, CUCSH, Universidad de Guadalajara. salcidoserrano@yahoo. com.mx cual se le representaría. En el mismo sentido, aunque desprovistos de una representación propia, se encuentran elementos de este sujeto en las indagacio-

Leticia Ruano Ruano (20I3). La identidad del laico apostólico: Acción Católica Mexicana. Guadalajara: Universidad de Guadalajara. 
nes sobre la forma de organización que significó la ACM en un México siempre heterogéneo y contradictorio.

En un tenor diferente, ocupándose de la construcción identitaria del laico a partir del concepto de un "nosotros" católico, la doctora Leticia Ruano Ruano realiza en $L a$ identidad del laico apostólico: Acción Católica Mexicana un escrupuloso estudio acerca de la organización y activismo acemero. El suyo es un cuidado ejercicio acerca de lo que significó pertenecer a la comunidad católica.

Para ello, reconstruye momentos de la experiencia de la acción social que materializan dos mujeres pertenecientes a la parroquia de la Capilla de Jesús. Esta investigación de "atenta escucha" puede considerarse un acercamiento a una de las expresiones singulares del sujeto católico en México, pues si bien se indaga la identidad, esta queda sujeta a la significación que le atribuyen quienes participaron e hicieron posible el catolicismo social.

Esta obra se estructura en cinco capítulos dedicados a dar cuenta de las cuestiones metodológicas, conceptuales, las relativas a las preguntas de estudio y la delimitación del sujeto, los elementos contextuales en diversas escalas, los condicionantes históricos y las características ponderadas, las definiciones religiosas e ideológicas, la representación de los otros, las prácticas sociales a nivel de la parroquia y la forma de organización.

En ellos se aborda la identidad de la ACM como práctica y proceso: es pensada en tanto resultado de las relaciones entre individuos y grupos católicos con la jerarquía eclesial, sobre todo en momentos de cambios socioculturales y políticos que hicieron "languidecer" la función organizadora de lo social que la Iglesia se atribuyó durante mucho tiempo, una organización dispuesta por una instancia clerical y condicionada por criterios jerárquicos y verticalistas que propiciaron que sus mejores momentos también fueran la razón de su decaimiento. 
Para dar cuenta de ello, la autora se pregunta cuál es la identidad de ACM, considerando las implicaciones contextuales en su dimensión espacial y temporal, y también de qué manera se establece esta identidad en los grupos de individuos.

El prolijo estudio de Ruano se caracteriza por un sustento metodológico derivado del cruce entre fuentes escritas y orales. Por supuesto, la revisión bibliográfica pertinente no está ausente, además de la consulta de distintos archivos, fondos especializados, documentos personales y hemerográficos, de tal manera que termina construyendo un soporte para la dimensión subjetiva implicada en la institución, la organización y el discurso católico.

Las coordenadas de análisis no presentan una variación significativa respecto de la manera en que ha sido pensado el catolicismo social en México, pues el punto de partida es la dimensión institucional entendida desde la jerarquía eclesial y conceptuada como el origen, desarrollo, consolidación y ocaso de la ACM; estas etapas son enriquecidas con los matices del sentido y el aporte existencial que la asociación cumplió, como lo dejan ver quienes dieron testimonio respecto de sus vivencias al ser parte de ella.

En este sentido, resulta de particular interés la atención que Ruano presta a los testimonios recuperados en la investigación, elaborados a partir de distintas entrevistas: las vivencias reivindicadas hacen las veces de referente para pasar revista a las prácticas y procesos de la acción social católica.

En este libro, se afirma que para el caso de la ACM, si bien su comienzo estuvo vinculado a la radicalidad, su fortalecimiento, en cambio, se debió a una combinación de un proyecto bien definido, el llevar la doctrina cristiana a la vida cotidiana, y, ante ello, a un posicionamiento integral, tolerante y disciplinado, pero también desplegado en un tono antagonista respecto del anticlericalismo de los 
Gobiernos mexicanos, en cuyo marco el sujeto católico se hizo presente ante la limitación de las prácticas de culto a la esfera privada. En este cuidadoso estudio, se entretejen tres vertientes de análisis: la social, la institucional y la vivencial, para mostrar el fundamento de la identidad que constituyó la ACM.

Lo institucional se relaciona con la concepción de la ACM como fuerza centralizadora de un movimiento laico organizado jerárquicamente, aun en los años posteriores a 1965 cuando la capacidad de reunir y organizar había disminuido. Lo social se refiere a la capacidad de vincular a personas, grupos e institución clerical, para proyectarlos como alteridades radicales frente a otros grupos, y al Gobierno con sus políticas seculares. Lo vivencial alude a la materialización de las expectativas de personas y grupos católicos que habrían aprendido a comprender el mundo de manera cristiana y que, desde su activismo social, buscaron que esto siguiera siendo fuente de sentido, más que la materialización de los propósitos de la jerarquía católica.

De acuerdo con la autora, una de las expresiones identitarias del catolicismo social tapatío se desplegó como proceso y práctica de quienes hicieron del ser católico, más allá de las determinaciones clericales, una configuración comunitaria parroquial.

Esta, como muchas otras definiciones identitarias, implicó hacer de otros grupos sociales, otras ideas y comprensiones del mundo, los enemigos de su propio ser católico; de ello surge la pregunta: ¿la identidad católica, a final de cuentas, es una identidad negativa, esto es, surge como sentido por su distinción con otras identidades, más que por los principios y valores evangélicos que propone?

Ante esta interrogante, una de las lecturas que se pueden hacer de la trayectoria de la ACM, gracias a la reflexión que la autora hace de la construcción de la identidad del laico apostólico, da elementos para problematizar la cuestión, 
pues desborda la definición con la que partió el análisis, lo que hace del estudio mismo una crítica a las elaboraciones conceptuales respecto de su potencial analítico y su capacidad para referir las expresiones singulares de lo que significa ser un laico apostólico, un militante de la causa de la recristianización.

En parte, esa limitación comprensiva de la noción de identidad puede ubicarse en que esta se delimitó con base en la postulación de principios y valores frente a su efectiva encarnación, cuya relevancia, no obstante que dichos principios y valores lograron un impulso discursivo y práctico, radica en que posibilitaron las formas de organización y cimentaron las motivaciones de los católicos, sin lo cual no habría activismo social católico (por lo cual se les puede situar como fuerza generadora). Así es como se pueden entender las implicaciones de una construcción de identidad que trata de prolongarse en el tiempo con base en los mismos principios.

Esta limitación comprensiva o desborde de experiencia quizá suceda porque toda identidad no es más que la generalización de algunos elementos que constituyen a un sujeto en un momento determinado.

Quizá también porque las preguntas que se hace la autora conciernen a la interioridad del sujeto católico y su autorreflexividad, así como a sus diferentes etapas o momentos. A modo de ejemplo, se menciona una de ellas: ¿cómo recuperar información sobre la identidad de una organización con setenta años de vida? Este "desborde" es uno de los aportes de la investigación La identidad del laico apostólico... que se deriva de incorporar la experiencia femenina de quienes desde el barrio de la Capilla de Jesús impulsaron el trabajo a favor de la recristianización.

Se dice que la identidad de ACM es una práctica y un proceso resultado de las interacciones entre personas y grupos católicos en un marco desde el cual resisten a través 
del trabajo de evangelización, de recristianización, ya que la preocupación es que se formen los individuos desligados de la religiosidad católica y su moral.

El civismo desplegado por los militantes de ACM sería católico, social y político desde la cotidianeidad. Esto es: los laicos habrían de ser el brazo social no sólo de defensa de los principios del catolicismo ante unas instituciones políticas y sociales que estaban cambiando, sino que pretenderían restaurar una vida católica en lo social, que consideraban se estaba perdiendo.

Entonces, en este preciso estudio sobre la constitución identitaria de la ACM, las vivencias son el puente para analizar las prácticas y los procesos en los que tienen lugar la identificación sobre sí mismos y la diferenciación respecto de los otros, de modo que en las narraciones están presentes apreciaciones sobre las escalas espaciales a través de lo familiar, lo parroquial, la diócesis, lo nacional, incluso lo mundial.

La identidad es explorada de manera transversal por las actitudes de los laicos apostólicos y el programa y estructura de la ACM, enfoque que significa un cambio en favor de la comprensión de la heterogeneidad de experiencias constitutivas de la acción social católica en Jalisco, hasta privilegiar lo vivencial de ese "ser católico". De manera acertada, la autora identifica que la concreción de un "nosotros" de la ACM es donde valores, normas, creencias y costumbres adquieren forma, más allá de figurar la centralización de los laicos a favor de la jerarquía católica.

Por supuesto, esto no significa que hubiese una profunda distinción entre las ideas de la institución católica, representada por la jerarquía, y los feligreses activistas. Por el contrario, muestra su efectiva correlación en función de equiparar a los otros como sus enemigos, fueran socialistas, comunistas, liberales, protestantes, revolucionarios, es decir, partícipes de cualquier perspectiva que pusiera

\section{6}


en entredicho su lugar social preeminente como base de la sociedad mexicana, más cuando lo que postulaban se oponía a las concepciones de la ACM en sus referencias religiosas, pero también en lo cívico, lo político y lo económico.

Entonces, si interesa mirar el entretejido institucional y subjetivo que hace posible hablar de una identidad como laico apostólico, debe leerse el libro de Leticia Ruano. Este permite entender a un sujeto surgido de la tensión entre dos proyectos de sociedad que se disputaban el sentido de las instituciones: el de una sociedad secularizada y el de una cristiana, el primero de los cuales sería visto como una amenaza política para la jerarquía eclesial, aunque para los laicos podría ser visto como un conjunto de momentos en los que afirmarían su pertenencia a una comunidad cuyo sentido socio-religioso revistió a la parroquia y la familia.

Por otra parte, en la perspectiva de estudio está presente una insinuada revisión crítica acerca de las relaciones entre los sexos, las cuales son altamente diferenciadas y organizadas de manera subordinante privilegiando la figura masculina, a pesar de ser las mujeres la vertiente más productiva de ese sujeto.

El estudio de Leticia Ruano lleva a repensar que la adscripción a la ACM por parte de las mujeres implicó la posibilidad de hacerse presentes socialmente, aun cuando fuera bajo la tutela y vigilancia de una organización, lo que abre una posibilidad de comprender las relaciones de género como una cuestión de subalternización de las mujeres a pesar de su protagonismo en el catolicismo social, o quizá fuera precisamente por eso que la sujeción se convertiría en una especie de institución de hecho.

Finalmente, se reitera la invitación a leer este libro si se busca entender la singularidad que hace las veces de soporte de una identidad que no termina de despojarse de ciertos arquetipos religiosos y socioculturales, a pesar de significar mucho más que los propósitos de una jerarquía 
eclesial interesada en permanecer como referencia de la vida social, pero que no puede ir más allá de los postulados cristianos; en estos radica y encuentra sus límites el desenvolvimiento de la acción social del catolicismo mexicano como comunidad de sentido. 